Research Article

\title{
Drought and Wetness Variability and the Respective Contribution of Temperature and Precipitation in the Qinghai-Tibetan Plateau
}

\author{
Lele Zhang $\mathbb{D}^{1,2,3}$ and Liming Gao $\mathbb{D}^{1,2,3}$ \\ ${ }^{1}$ College of Geography Science, Qinghai Normal University, Xining 810008, China \\ ${ }^{2}$ MOE Key Laboratory of Tibetan Plateau Land Surface Processes and Ecological Conservation, Xining 810008, China \\ ${ }^{3}$ Qinghai Province Key Laboratory of Physical Geography and Environmental Process, Xining 810008, China
}

Correspondence should be addressed to Lele Zhang; zhang1986lele@163.com

Received 29 April 2021; Revised 19 August 2021; Accepted 7 September 2021; Published 29 September 2021

Academic Editor: Roberto Coscarelli

Copyright $(2021$ Lele Zhang and Liming Gao. This is an open access article distributed under the Creative Commons Attribution License, which permits unrestricted use, distribution, and reproduction in any medium, provided the original work is properly cited.

\begin{abstract}
Quantifying drought and wetness fluctuations is of great significance to the regional ecological environment and water resource security, especially in the fragile Qinghai-Tibetan Plateau (QTP). In this paper, the standardized precipitation evapotranspiration index (SPEI) was calculated based on the observed data and China Meteorological Forcing Dataset (CMFD) in the QTP for the period of 1979-2015, and the drought and wetness evolution based on the SPEI series and respective contribution of temperature and precipitation were also analyzed. Results indicated that meteorological stations are mainly concentrated in the eastern part of the plateau, which cannot reflect the drought and wetness trend of the whole QTP. The linear trend and Mann-Kendall test revealed that SPEI series calculated based on CMFD data at 1-, 3-, 6-, 9-, 12-, and 24-month time scales all showed significant upward trend $(p<0.01)$, indicating that the QTP as a whole tended to be wetter. Spatially, the regions with significant drying $(p<0.1)$ and increased drought probability were mainly concentrated in the Qaidam Basin and the southern part of the QTP, and the mean contribution rates of temperature and precipitation variability to SPEI trend in these regions were $60 \%$ and $-11 \%$, respectively. The regions with significant wetting $(p<0.1)$ and decreased drought probability were mainly concentrated in the northeast, central, and western parts of the plateau, and the mean contribution rates of temperature and precipitation variability to SPEI trend were $-9 \%$ and $61 \%$ in these regions. From the statistics in different climatic regions, most of the arid and humid regions in the QTP tended to be drier, while the semiarid regions tended to be wetter.
\end{abstract}

\section{Introduction}

Drought and wetness fluctuations, which are closely related to precipitation and evapotranspiration variation [1], have profound influences on agriculture and ecosystems. Over the past few decades, the global climate has changed remarkably [2]. Ground observation, remote sensing, and reanalysis data revealed that temperature is rising in most regions of the world $[3,4]$. Although the spatial difference of precipitation change was relatively large [5], the frequency of extreme precipitation had increased extensively in most parts of the world $[6,7]$. With the changes of temperature and precipitation, the state of drought and wetness was also changing. Globally, climate change is leading dry regions to become drier and wet regions to become wetter $[8,9]$, and the frequency of extreme drought and flood events would further increase in the 21st century [10-12]. These extreme events can cause billions of dollars in losses and affect more people than any other climate-related disaster [13]. Therefore, it is of great significance to comprehensively understand the drought and wetness change trend.

Many meteorological drought indexes had been developed for quantifying drought and wetness fluctuations, including the Palmer drought severity index (PSDI) [14], standardized precipitation index (SPI) [15], China-Z index (CZI) [16], standardized precipitation evapotranspiration 
index (SPEI) [17], and soil wetness deficit index (SWDI) [18]. Among these indexes, SPI and SPEI are easy to obtain and widely used for drought and wetness changes and their impact on agriculture and ecological environment in many countries and regions of the world [19-25]. The main advantage of the SPI is that it is calculated at multi-time scales and can monitor different drought types [26, 27]. However, only precipitation is used in the calculation of the SPI [17]. The index cannot reflect the influence of temperature change on the drought and wetness conditions. Compared with SPI, SPEI is calculated based on the process of surface water balance and also introduces the multi-time scale character used in SPI calculation [17, 28]. Chen et al. [29] compared the monitoring results of SPI, PDSI, and SPEI in China and found that the meteorological drought monitored by SPEI was better than that monitored by SPI and PDSI. The results obtained by Zarei et al. [30] also showed that the accuracy of SPEI in monitoring drought events is higher than that of SPI and reconnaissance drought index (RDI) in Iran. Furthermore, previous studies had also shown that SPEI variation is highly correlated with vegetation index, crop growth state, and soil water storage change [31-33], so it has a wide application potential in water resource management, agricultural production, and other fields in the future.

The QTP is recognized as the water tower of Asia and can influence the Asian monsoon through its mechanical and thermal forcing [34-37]. As a sensitive and fragile area, the evolution of drought and wetness in the QTP has attracted extensive attention. Shi and Liu [38] analyzed the characteristics of drought events over the continent in the Eastern Hemisphere based on the SPEI data and found that the QTP had been one of the regions with high variance. Wang et al. [39] used the high-accuracy self-calibrating Palmer drought severity index (sc_PDSI) to investigate the drought variation in China and found that northern Tibetan Plateau and southern Tibetan Plateau experienced a wetting trend between 1961 and 2009. Feng et al. [40] investigated spatialtemporal patterns of meteorological drought in the QTP and its surrounding areas and revealed that the QTP became wetter in spring during 1970-2017. Chen et al. [41] divided China into six climatic regions and analyzed the characteristics of drought and wetness trend based on SPEI, PDSI, and sc_PDSI and proposed that the QTP became wetter during 1961-2012. It should be noted that most of these conclusions are based on the observed data. However, the meteorological stations are mainly concentrated in the eastern part of the plateau, while the drought and wetness conditions in the west with few stations had received little attention. Additionally, the precipitation and temperature variability is the main factor that directly affects the change trends of drought/wetness, and previous studies had shown that the temperature and precipitation in the QTP both showed increasing trend [42-44]. However, it is still not clear that which is the main factor that dominates the drought and wetness trend in the plateau.

In this study, both the observed data from 50 meteorological stations and CMFD high-resolution meteorological forcing data were used to analyze drought and wetness condition evolutions over the QTP. The main objectives of this study were to (1) assess the spatiotemporal variation characteristics of drought and wetness in the QTP during 1979 to 2015 and (2) quantify the respective contributions of temperature and precipitation variability to drought and wetness trend in the QTP. The rest of the article is arranged as follows. The basic conditions and meteorological data in the QTP and the methods used in this paper are introduced in Section 2. In Section 3, the spatiotemporal evolution of drought and wetness is analyzed, and the respective contributions of temperature and precipitation variability to drought and wetness trend are calculated. The discussion and conclusions are given in Sections 4 and 5, respectively.

\section{The Study Area, Data, and Methods}

2.1. Study Area and Data Sources. The QTP lies in the southwest of China, including most of the Qinghai Province and Tibet Autonomous Region and a few parts of Xinjiang Uygur Autonomous Region, Gansu, Sichuan, and Yunnan (Figure 1). The Altun Mountains, Qilian Mountains, and Qaidam Basin are located in the north of the plateau, and the Himalaya Mountains are located in the southwest. The QTP covers a total area of $257 \times 10^{4} \mathrm{~km}^{2}$, of which $122.2 \times 10^{4} \mathrm{~km}^{2}$ is permafrost area [45]. With an average elevation of more than 4500 meters, the QTP is the highest plateau in the world, so it is also known as the "Third Pole." In addition, the QTP is also the headstream of many major rivers (including the Yangtze River, Yellow River, Lancang River, Nujiang River, and so on) in the world, and China's largest lake (Qinghai Lake) is also located in the northeast of the plateau, so it is also known as the "Water Tower of Asia." The climate on the plateau is alternately controlled by monsoon in the summer and westerlies in the winter [46]. Precipitation is mainly concentrated in the warm season, and the light precipitation is dominant in winter [47]. Spatially, the central and southern parts of the plateau are mainly controlled by the Indian monsoon, and the annual maximum precipitation can reach more than $1000 \mathrm{~mm}$, while the western and northern parts are controlled by the westerlies, and the annual precipitation is relatively low, and the annual precipitation in the Qaidam Basin in the north is even less than $100 \mathrm{~mm}$ [48]. The temperature is relatively high due to low latitude and altitude in the southeast of the plateau, while in the west, the temperature is relatively low due to high altitude [49].

Observed monthly temperature and precipitation were used for SPEI calculations in this study. The observed data (1979-2015) for 50 sites in the QTP (Figure 1) were derived from the National Meteorological Information Center (https://www.data.cma.cn/). These data were obtained from the daily value statistics of meteorological elements, and the production process strictly followed the standards and methods formulated by the National Meteorological Administration of China. The accuracy of the data had been verified and also had been widely used in the research of China's climate change and hydrological process $[50,51]$. 


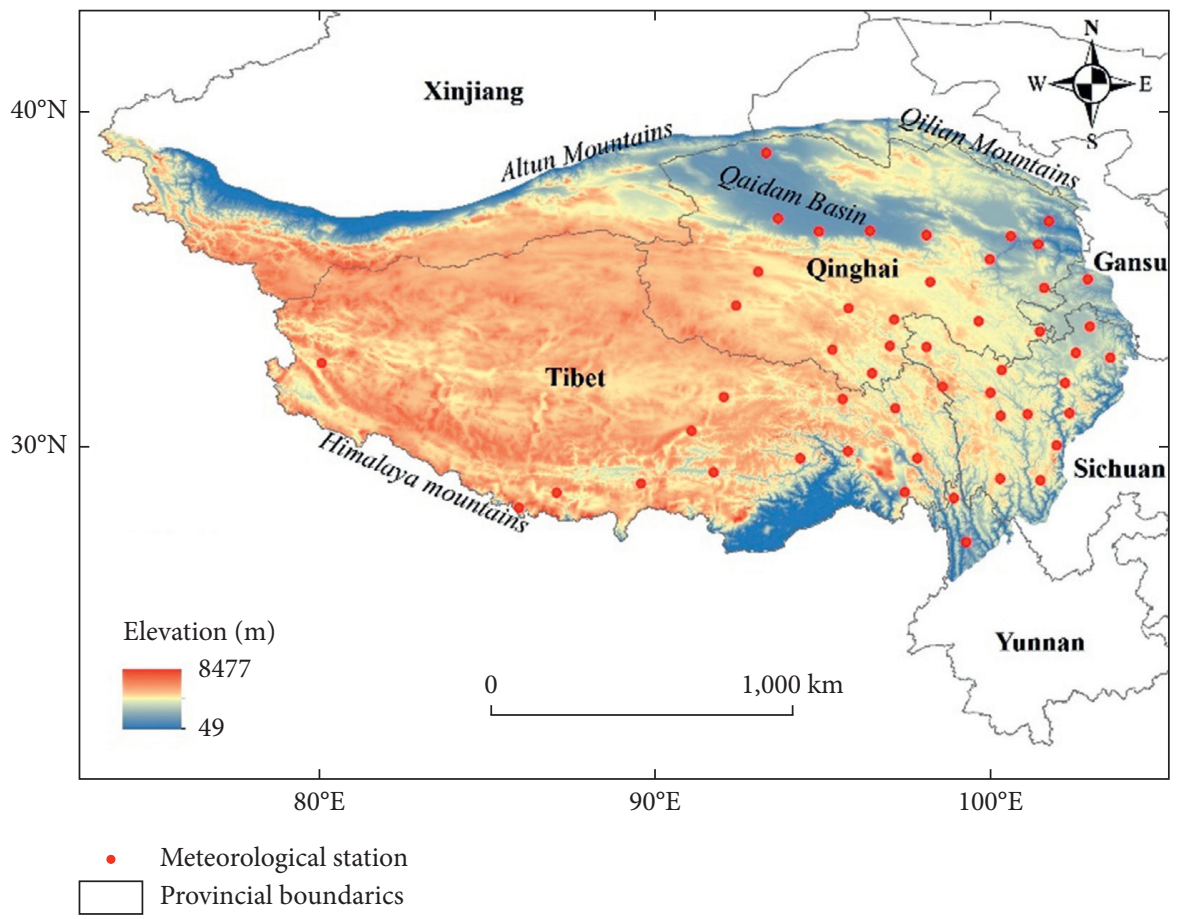

Figure 1: Topographic map of the Qinghai-Tibetan Plateau (adapted from the geospatial data cloud at Beijing (https://www.gscloud.cn/)).

Considering the sparsity of observation sites in the QTP, the CMFD data offered by the National Tibetan Plateau Data Center (https://www.data.tpdc.ac.cn/) were also used for SPEI calculations. The CMFD data constitute a near-surface meteorological forcing dataset and cover the China domain at a 3-hourly time step and a spatial resolution of $0.1^{\circ}$, spanning from 1979 to 2015 . It was made through fusion of ground-based observations of approximately 700 stations in China with several gridded datasets including GLDAS, MERRA, GEWEX-SRB, and TRMM 3B42 v7 [52]. The meteorological elements include near-surface temperature, pressure, specific humidity, wind speed, ground downward short-wave radiation, downward long-wave radiation, and precipitation rate. The CMFD data had been widely used in the study of the climate and hydrology of the QTP $[53,54]$.

\subsection{SPEI for Determining Drought and Wetness Conditions.} SPEI is an improved drought index of SPI designed by Vicente-Serrano et al. [17]. It is calculated based on the process of surface water balance and also introduces the multi-time scale character used in SPI calculation, which fully combines the advantages of SPI and PDSI. Because of its advantages, it had been widely used in drought monitoring in many studies [40,41]. Based on SPEI calculations, drought and wetness can be classified into seven categories as listed in Table 1. Calculation of the index is performed using the computer program SPEI Calculator, which is developed and maintained by the Institutional Repository of the Spanish National Research Council. Software and documentation are available online for downloading (https://www.digital.csic.es/). The default method for calculating the potential evapotranspiration in the software is
TABLE 1: Drought and wetness classification based on the SPEI value $[17,28,30]$.

\begin{tabular}{lc}
\hline Category & SPEI value \\
\hline Extremely wet & SPEI $\geq 2$ \\
Moderately wet & $1.5 \leq \mathrm{SPEI}<1.99$ \\
Slightly wet & $1 \leq \mathrm{SPEI}<1.49$ \\
Near normal & $-0.99<\mathrm{SPEI}<0.99$ \\
Mild drought & $-1.49<\mathrm{SPEI} \leq-1$ \\
Moderate drought & $-1.99<\mathrm{SPEI} \leq-1.5$ \\
Extreme drought & $\mathrm{SPEI} \leq-2$ \\
\hline
\end{tabular}

the Thornthwaite method. Although the potential evapotranspiration estimated by this method in winter and spring in China has certain differences from other methods, the overall estimation of the potential evapotranspiration form Thornthwaite and other methods is very comparable $[40,55,56]$. By providing a text file containing temperature and precipitation data, geographic latitude, time, and other basic information, the program can automatically calculate SPEI series at different time scales. In this study, SPEI values were calculated both based on the observed and CMFD data in the QTP for the period of 1979-2015.

According to the classification criteria in Table 1, the frequency of each drought and wetness category during a period can be obtained, and the probability of each category is calculated as follows [57]:

$$
p_{i}=\frac{f_{i}}{F} \times 100 \%
$$

where $p_{i}$ and $f_{i}$ are the probability (\%) and frequency of $i$ th drought and wetness category during a period, respectively, and $F$ is the total number of data points. 


\subsection{Statistical Methods}

2.3.1. Methods for Detecting Drought and Wetness Trends. Drought and wetness trends are indicated by the linear trends of SPEI series in this study. The Mann-Kendall test is used to determine the significance of the trends. The Mann-Kendall (MK) test does not require samples to follow a certain distribution and is also not affected by some outliers $[58,59]$. In previous studies, the MK method had been widely used in the trend analysis of time series in meteorological, hydrological, and ecological fields $[19,60]$. The method is based on the $Z$ value to judge the change trend of time series and is computed as follows [40, 61].

Calculate the test statistical variable $S$ based on the SPEI series $\left(x_{1}, x_{2}, x_{3}, \ldots, x_{n}\right)$ :

$$
S=\sum_{i=1}^{n-1} \sum_{j=i+1}^{n} \operatorname{sgn}\left(x_{j}-x_{i}\right),
$$

where $\operatorname{sgn}(x)$ represents the sign function and can be expressed as follows:

$$
\operatorname{sgn}\left(x_{j}-x_{i}\right)= \begin{cases}1, & x_{j}-x_{i}>0, \\ 0, & x_{j}-x_{i}=0, \\ -1, & x_{j}-x_{i}<0\end{cases}
$$

The variance of $S$ can be expressed as

$$
\operatorname{Var} S=\frac{n(n-1)(2 n+5)}{18}
$$

The standard test statistical variable $Z$ is computed as

$$
Z= \begin{cases}\frac{S-1}{\sqrt{\operatorname{Var} S}}, & S>0, \\ 0, & S=0, \\ \frac{S+1}{\sqrt{\operatorname{Var} S}}, & S<0 .\end{cases}
$$

When the $Z$ value is positive, it represents an increasing trend, while negative $Z$ value means a decreasing trend. When $|Z|$ is greater than $1.28,1.64$, and 2.32 , it means that the corresponding trend of time series has passed the significance test at $p<0.1, p<0.05$, and $p<0.01$ levels, respectively.

2.3.2. Quantification of the Respective Contributions of Temperature and Precipitation. A simple method adapted based on the algorithm proposed by $\mathrm{Wu}$ and Chen [62] was used for quantifying the respective contributions of the temperature and precipitation variability to the drought and wetness trends, and the calculation flow of this method is as follows:

(1) The monthly temperature and precipitation data from 1979 to 2015 were divided into 12 groups by month, respectively, and the linear detrending method is used for these groups. The linear detrending method is described as follows:

$$
Y_{i}=y_{i}-\gamma(i-1979) \text {, }
$$

where $Y_{i}$ is the detrended monthly precipitation or temperature in the $i$ th year $(i=1979,1980, \ldots$, 2015), $y_{i}$ is the original monthly precipitation or temperature in the $i$ th year, and $\Upsilon$ is the precipitation or temperature trend during 1979-2015.

(2) According to the results of the previous step, the SPEI series under 3 climate scenarios can be obtained. The first SPEI time series $\left(S P E I_{o}\right)$ was calculated based on the original meteorological data, the second $\left(S P E I_{D p}\right)$ was calculated using the original temperature records and detrended precipitation data, and the third $\left(S P E I_{D t}\right)$ was calculated using the detrended temperature data and observed precipitation records.

(3) The factors affecting the variability of $S P E I_{o}$ can be divided into three categories, including temperature, precipitation, and other factors. The other factors mean the factors that can affect drought and wetness conditions except temperature and precipitation. When the slope of $S P E I_{o}$ series $\left(S \_S P E I_{o}\right)$ is greater than 0 , it means that this grid point tends to be wetter during 1979-2015, and the contribution rates $(C r)$ of the three factors are calculated as follows:

$$
\begin{aligned}
& C r_{-} T=\frac{S_{-} S P E I_{D p}}{\left|S_{-} S P E I_{D p}\right|+\left|S_{-} S P E I_{D t}\right|+\left|S_{-} S P E I_{o}-S P E I_{D p}-S_{-} S P E I_{D p}\right|} \times 100 \%, \\
& C r_{-} P=\frac{S_{-} S P E I_{D t}}{\left|S_{-} S P E I_{D p}\right|+\left|S_{-} S P E I_{D t}\right|+\left|S_{-} S P E I_{o}-S P E I_{D p}-S_{-} S P E I_{D p}\right|} \times 100 \%, \\
& C r_{-} O=\frac{S_{-} S P E I_{o}-S_{-} S P E I_{D p}-S_{-} S P E I_{D p}}{\left|S_{-} S P E I_{D p}\right|+\left|S_{-} S P E I_{D t}\right|+\left|S_{-} S P E I_{o}-S P E I_{D p}-S_{-} S P E I_{D p}\right|} \times 100 \%,
\end{aligned}
$$


where $S \_S P E I_{o}, S \_S P E I_{D p}$, and $S \_S P E I_{D t}$ represent the linear slopes of $S P E I_{o}, S P E I_{D p}$, and $S P E I_{D t}$ time series and $C r_{-} T$, $\mathrm{Cr}_{-} P$, and $\mathrm{Cr}_{-} \mathrm{O}$ are the $\mathrm{Cr}$ values of temperature, precipitation, and other factors. If $\mathrm{Cr}>0$, it means that this factor has a positive contribution to the wetting trend, and the greater the absolute value is, the greater the contribution is.
If $C r<0$, it means that this factor has a negative contribution to the wetting trend. If $C r=0$, it means there is no contribution. When $S \_S P E I_{o}<0$, it means that this grid point tends to be drier, and the contribution rates are calculated as follows:

$$
\begin{aligned}
& C r_{-} T=\frac{-S_{-} S P E I_{D p}}{\left|S_{-} S P E I_{D p}\right|+\left|S_{-} S P E I_{D t}\right|+\left|S_{-} S P E I_{o}-S P E I_{D p}-S_{-} S P E I_{D p}\right|} \times 100 \%, \\
& C r_{-} P=\frac{-S_{-} S P E I_{D t}}{\left|S_{-} S P E I_{D p}\right|+\left|S_{-} S P E I_{D t}\right|+\left|S_{-} S P E I_{o}-S P E I_{D p}-S_{-} S P E I_{D p}\right|} \times 100 \%, \\
& C r_{-} O=\frac{-\left(S_{-} S P E I_{o}-S_{-} S P E I_{D p}-S_{-} S P E I_{D p}\right)}{\left|S_{-} S P E I_{D p}\right|+\left|S_{-} S P E I_{D t}\right|+\left|S_{-} S P E I_{o}-S P E I_{D p}-S_{-} S P E I_{D p}\right|} \times 100 \% .
\end{aligned}
$$

If $\mathrm{Cr}>0$, it means that this factor has a positive contribution to the drying trend. If $\mathrm{Cr}<0$, it means that this factor has a negative contribution to the drying trend. If $\mathrm{Cr}=0$, it means there is no contribution. It should be noted that only the contributions of temperature and precipitation variability to the drought and wetness trends were analyzed in this study.

\section{Results}

3.1. Spatiotemporal Variation of SPEI Series in the QTP. Based on the temperature and precipitation data recorded at 50 meteorological stations and 25711 CMFD grid points from 1979 to 2015, the SPEI values at 1-, 3-, 6-, 9-, 12-, and 24-month time scales were calculated. The variation trend of SPEI time series at each station and grid point is given by using the linear slope and MK test (Figure 2). As can be seen from Figures 2(a)-2(f), the variation trend of SPEI time series at different time scales is consistent and the SPEI time series of more than $84 \%$ stations showed a downward trend. Since the meteorological stations are mainly concentrated in the eastern part of the QTP, it is believed that the eastern part of the plateau tended to be drier during 1979 and 2015 . Figures 2(g)-2(l) show the results obtained based on CMFD data. According to statistics, the grid points with a decreasing trend of SPEI are less than 38\%, mainly concentrated in the southeast of QTP and Qaidam Basin, which is consistent with the conclusion obtained based on meteorological stations. However, in the central and western parts of the plateau, SPEI time series showed upward trend during 1979 and 2015, indicating that these areas tended to be wetter.

In order to characterize the drought and wetness trend in the whole QTP, the SPEI series at 1-, 3-, 6-, 9-, 12-, and 24month time scales were averaged over the 25711 CMFD pixels, and the temporal evolution of these SPEI series is displayed in Figure 3. It can be seen from Figure 3 that the fluctuation of SPEI series calculated by small time scale is relatively large, while the fluctuation is relatively small by large time series. The SPEI values at all time scales were mainly negative before 2001 and positive after 2001. The results of the linear slope and MK test showed that all SPEI time series showed an obvious upward trend $(p<0.01)$, which means that the QTP tended to be wetter as a whole during 1979 and 2015.

3.2. Probability of Drought and Wetness Occurrences. The probabilities of occurrence for each drought and wetness category at all CMFD grids in the QTP were calculated. In order to analyze the dynamic change of occurrence probability of each drought and wetness category, the whole period was divided into two subperiods: the first is from 1979 to 2000 (Period I) and the second is from 2001 to 2015 (Period II). As shown in Figure 4, the difference between probabilities of drought and wetness occurrences based on SPEI at different time scales were small in the whole plateau. During 1979-2000, the probability of mild drought was the highest while the probability of slightly wet was the highest during 2001-2015. The probabilities of extreme drought and moderate drought did not change much between the two subperiods. Compared with Period I, the probability of extreme drought increased slightly in Period II, and the probability of moderate drought decreased slightly. However, the probabilities of mild drought, slightly wet, moderately wet, and extremely wet were different between the two subperiods. In Period II, the probability of mild drought decreased, while the probabilities of slightly wet, moderately wet, and extremely wet increased.

The spatial differences of drought and wetness probability variations in the QTP were also analyzed. Considering that the probabilities calculated by different time scales were close, only SPEI calculated at 12-month time scales was used for statistics. Figure 5 shows the probability of each drought and wetness category of all CMFD pixels in 2001-2015 minus that in 1979-2000. If the value obtained by subtraction is positive, it means that the probability in 2001-2015 has increased compared with that in 1979-2000; 


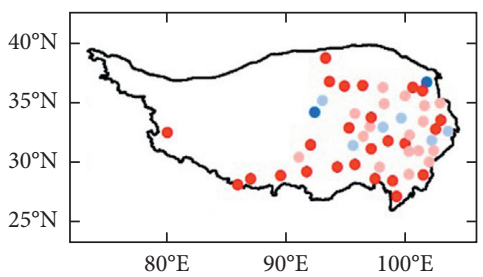

- Decreased significantly $(\mathrm{p}<0.1)$

- Decreased but not significantly ( $\mathrm{p}>0.1$ )

- Increased but not significantly $(p>0.1)$

- Increased significantly $(\mathrm{p}<0.1)$

(a)

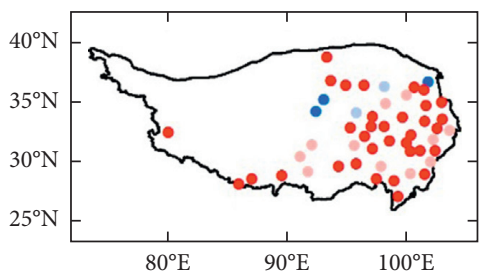

- Decreased significantly $(\mathrm{p}<0.1)$

- Decreased but not significantly ( $p>0.1$ )

- Increased but not significantly $(p>0.1)$

- Increased significantly $(\mathrm{p}<0.1)$

(d)

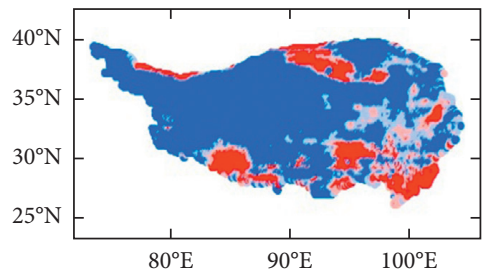

- Decreased significantly $(\mathrm{p}<0.1)$

- Decreased but not significantly $(\mathrm{p}>0.1)$

- Increased but not significantly $(\mathrm{p}>0.1)$

- Increased significantly $(\mathrm{p}<0.1)$

(g)

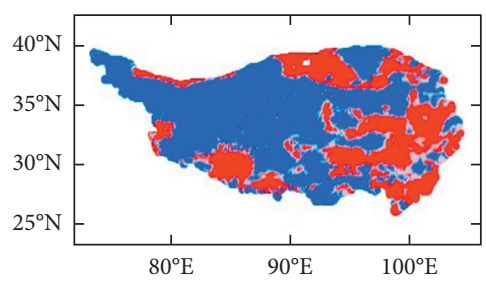

- Decreased significantly $(p<0.1)$

- Decreased but not significantly $(p>0.1)$

- Increased but not significantly $(p>0.1)$

- Increased significantly $(p<0.1)$

(j)

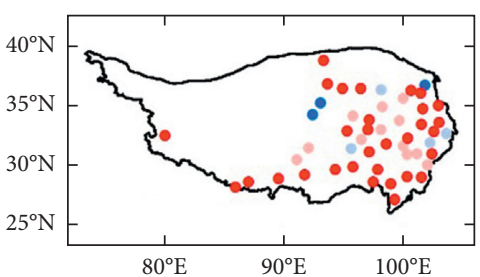

- Decreased significantly $(\mathrm{p}<0.1)$

- Decreased but not significantly $(\mathrm{p}>0.1)$

- Increased but not significantly $(p>0.1)$

- Increased significantly $(\mathrm{p}<0.1)$

(b)

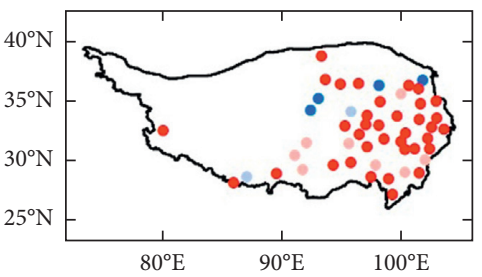

- Decreased significantly $(\mathrm{p}<0.1)$

- Decreased but not significantly $(p>0.1)$

- Increased but not significantly $(p>0.1)$

- Increased significantly $(p<0.1)$

(e)

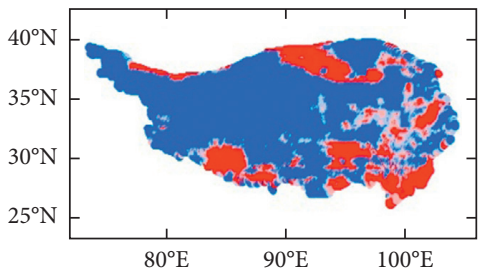

- Decreased significantly $(\mathrm{p}<0.1)$

- Decreased but not significantly $(p>0.1)$

- Increased but not significantly ( $p>0.1)$

- Increased significantly $(p<0.1)$

(h)

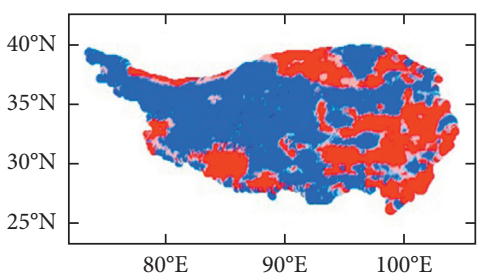

- Decreased significantly $(\mathrm{p}<0.1)$

- Decreased but not significantly $(p>0.1)$

- Increased but not significantly $(p>0.1)$

- Increased significantly $(p<0.1)$

(k)

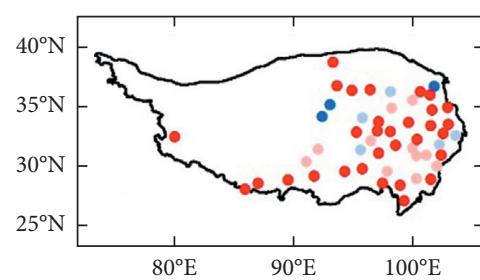

- Decreased significantly $(\mathrm{p}<0.1)$

- Decreased but not significantly $(p>0.1)$

- Increased but not significantly $(p>0.1)$

- Increased significantly $(\mathrm{p}<0.1)$

(c)

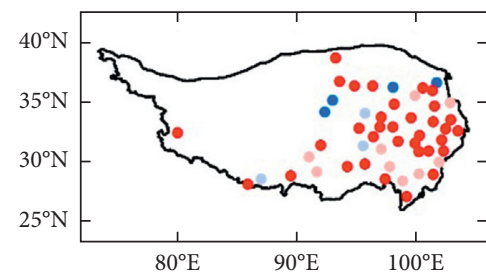

- Decreased significantly $(\mathrm{p}<0.1)$

- Decreased but not significantly $(p>0.1)$

- Increased but not significantly $(\mathrm{p}>0.1)$

- Increased significantly $(\mathrm{p}<0.1)$

(f)

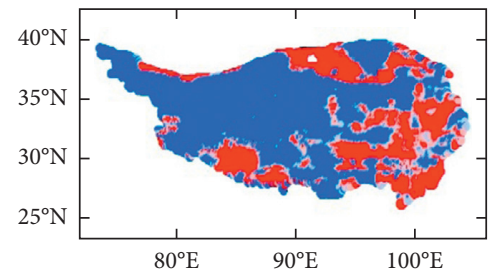

- Decreased significantly $(\mathrm{p}<0.1)$

- Decreased but not significantly $(\mathrm{p}>0.1)$

- Increased but not significantly $(p>0.1)$

- Increased significantly $(\mathrm{p}<0.1)$

(i)

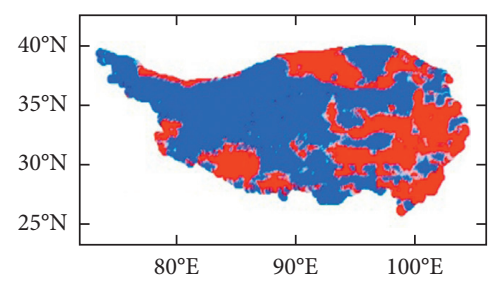

- Decreased significantly $(\mathrm{p}<0.1)$

- Decreased but not significantly $(p>0.1)$

- Increased but not significantly $(p>0.1)$

- Increased significantly $(\mathrm{p}<0.1)$

(1)

FIGURE 2: Spatial distributions of the Mann-Kendall trend statistic for SPEI at different time scales for the period 1979-2015. (a)-(f) are the SPEI trends based on observed data, and (g)-(l) are the SPEI trends based on the CMFD data. (a) SPEI-1. (b) SPEI-3. (c) SPEI-6. (d) SPEI-9. (e) SPEI-12. (f) SPEI-24. (g) SPEI-1. (h) SPEI-3. (i) SPEI-6. (j) SPEI-9. (k) SPEI-12. (l) SPEI-24.

otherwise, the probability has decreased. As shown in Figure 5(a), the probability of extreme drought in most areas of the southeastern, southwestern, and northwestern parts of the QTP increased during 2001-2015 compared with that during 1979-2000. However, except for the Qaidam Basin,
Southern Xinjiang, and the southeast of Tibet, the increased probabilities of extreme drought in other regions were less than $10 \%$. In the central and northeastern parts of the plateau, the probability of extreme drought decreased, with a decrease of less than $10 \%$ in almost all regions. From 


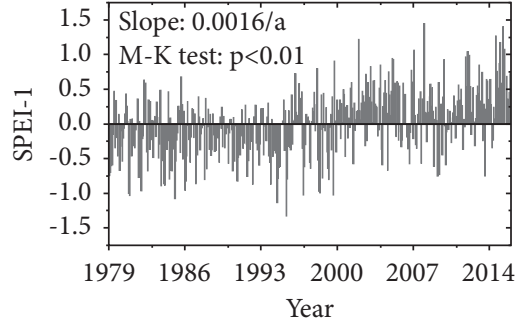

(a)

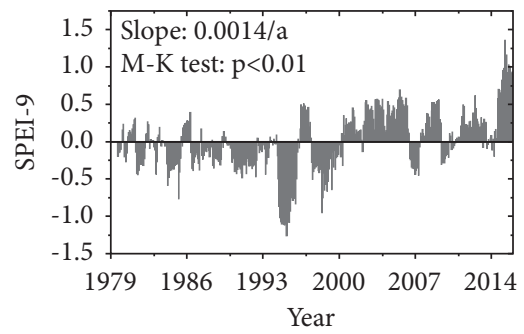

(d)

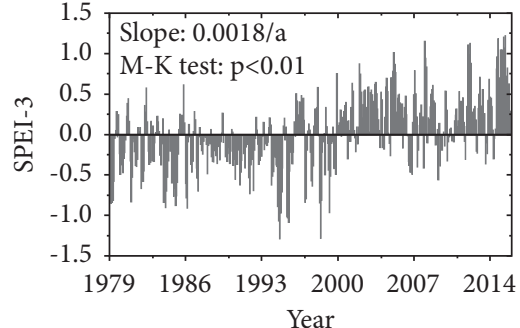

(b)

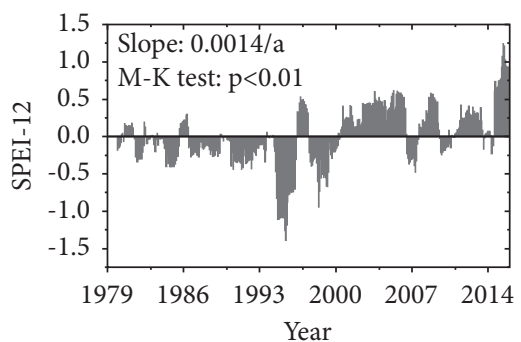

(e)

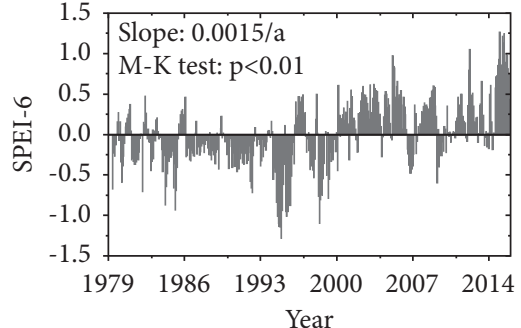

(c)

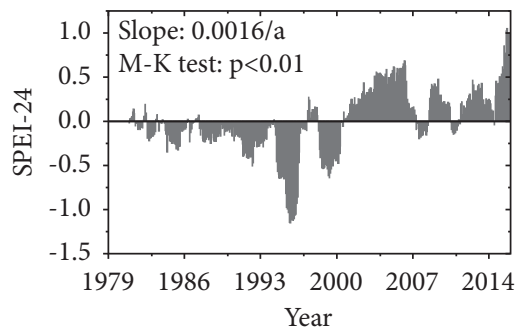

(f)

FIgURE 3: Temporal variability of the SPEI values at 1-, 3-, 6-, 9-, 12-, and 24-month time scales for the period 1979-2015 in the QTP.

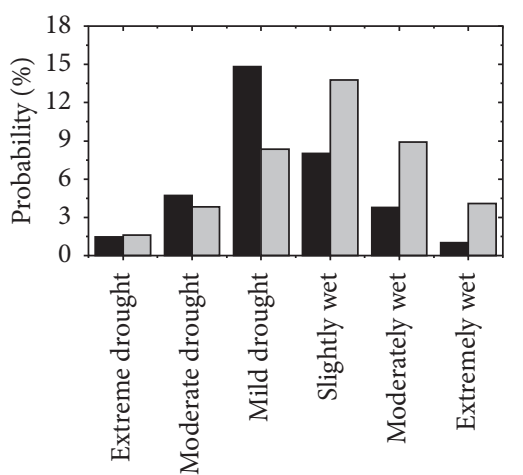

- Before 2001

$\square$ After 2001

(a)

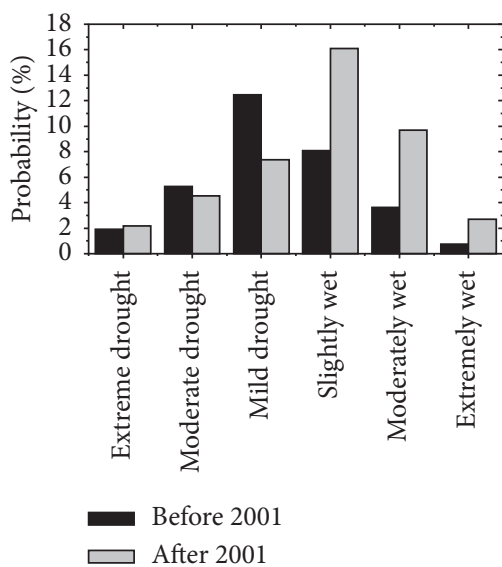

(d)

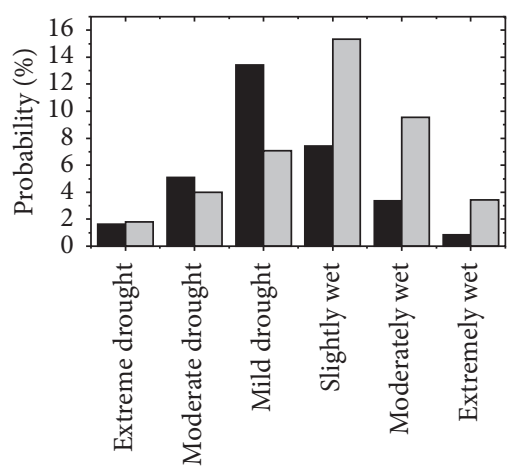

Before 2001

(b)

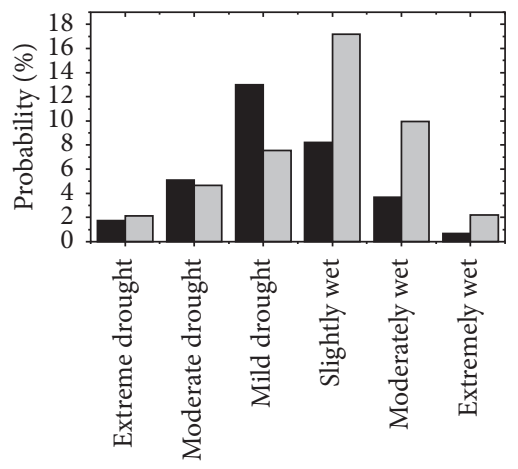

Before 2001

(e)

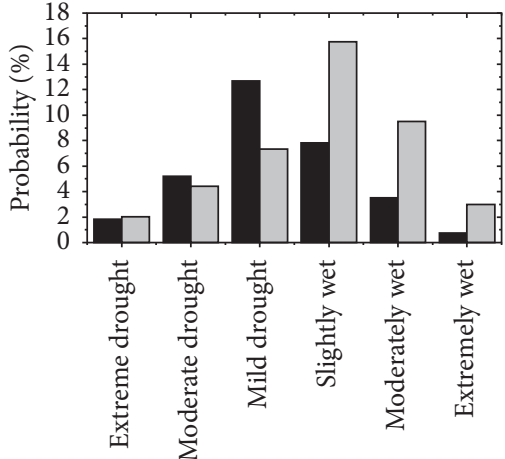

- Before 2001

$\square$ After 2001

(c)

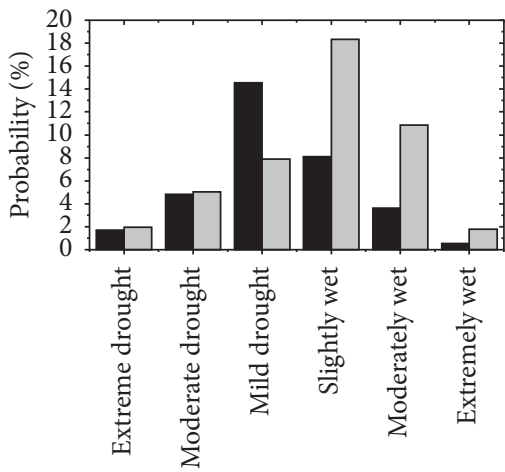

- Before 2001 After 2001

(f)

FIgURE 4: Changes of drought and wetness probability before and after 2001. (a) SPEI-1. (b) SPEI-3. (c) SPEI-6. (d) SPEI-9. (e) SPEI-12. (f) SPEI-24. 


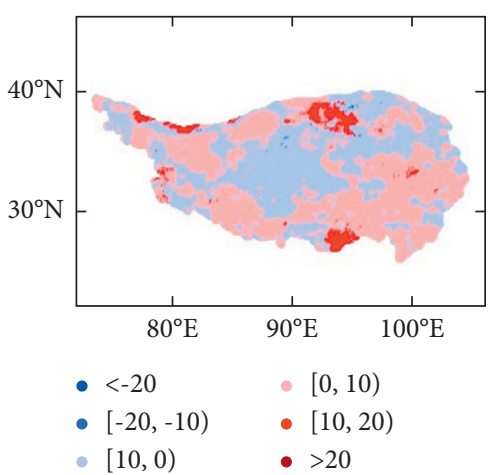

(a)

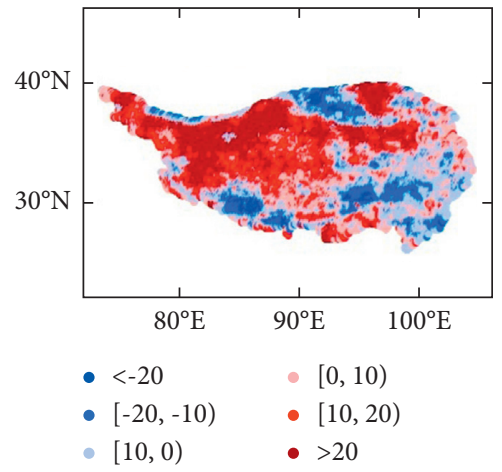

(d)

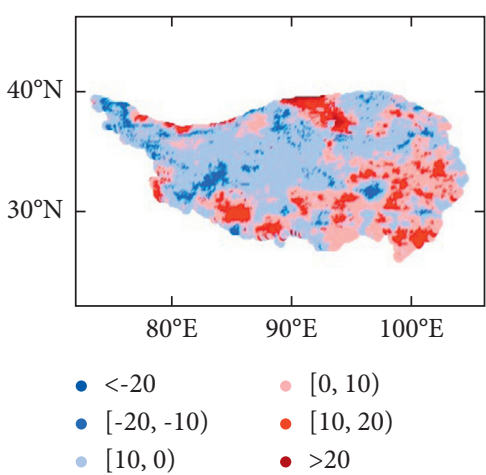

(b)

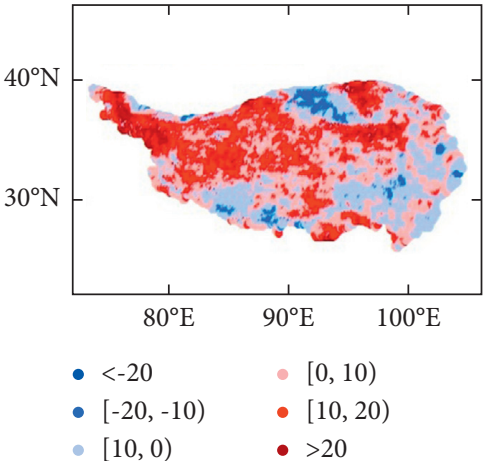

(e)

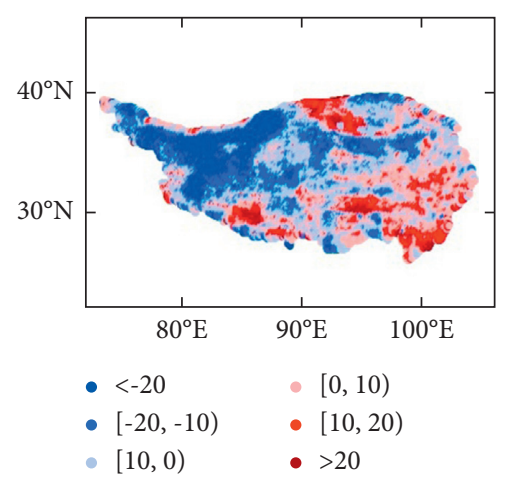

(c)

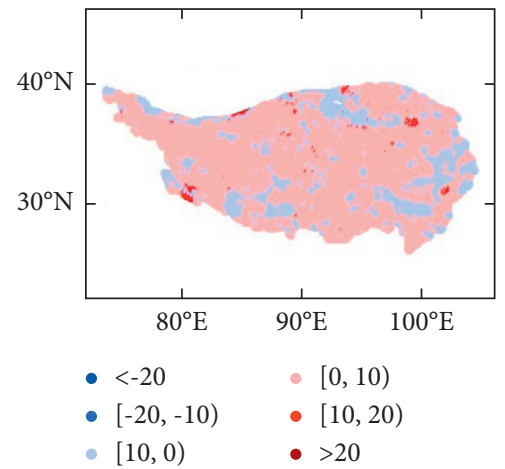

(f)

FIGURE 5: Drought and wetness probability variation before and after 2001 in the QTP (after 2001 values minus before 2001). The red area represents that the probability in 2001-2015 has increased compared with that in 1979-2000, while the blue area represents that the probability has decreased. (a) Extreme drought. (b) Moderate drought. (c) Mild drought. (d) Slightly wet. (e) Moderately wet. (f) Extremely wet.

Figures 5(b) and 5(c), it can be seen that the probabilities of moderate drought and mild drought in the Qaidam Basin and the southeast of plateau increased obviously during 2001-2015, while the probability mainly decreased in other regions, but the decreased value of the probability of mild drought was higher than that of moderate drought. During 2001-2015, the probabilities of slightly wet and moderately wet showed the opposite trend. The probabilities of slightly wet and moderately wet decreased in the Qaidam Basin and the southeast of the plateau but increased in other regions (Figures 5(d) and 5(e)). It can be seen from Figure 5(f) that the probability of extremely wet increased in most other regions except the Qaidam Basin. According to this result, the probability of drought had increased and the probability of wetness had decreased obviously in the regions that tended to be drier. However, the results were opposite in the regions that tended to be wetter.

3.3. The Respective Contributions of Temperature and Precipitation Variability to the Drought and Wetness Trend. Using the method introduced in Section 2.3.2., the $\mathrm{Cr}$ values of the temperature and precipitation variability to the drought and wetness trends for 25711 grids in the QTP were calculated. Generally, the increase of the temperature and precipitation results in positive and negative contribution rates for the SPEI trend, respectively, in the drought-prone regions. However, in the regions that tend to be wetter, the increase of the temperature and precipitation results in negative contribution and positive contribution rate for the SPEI trend, respectively. Figures 6(a) and 6(b) show the $\mathrm{Cr}$ values of the precipitation and temperature variability in drought-prone regions. It can be seen that the contribution rates of temperature in these regions range from $-33 \%$ to $100 \%$, with an average value of $60 \%$. The contribution rates of precipitation are between $-100 \%$ and $50 \%$, and the average is $-11 \%$. The increase of temperature was the main reason that the Qaidam Basin and southeast and southwest of Qinghai-Tibetan Plateau tended to be drier during 1979-2015. Spatially, the $\mathrm{Cr}$ values of temperature to SPEI trend in the Qaidam Basin were positive, while the contributions of precipitation were negative. However, in some areas of the southeast and southwest of the QTP, the contribution rates of temperature and precipitation to the drought trend were both positive. Figures 6(c) and 6(d) show the $\mathrm{Cr}$ values of the precipitation and temperature variability in the regions that tend to be wetter. The $\mathrm{Cr}$ values of temperature in these regions ranged from $-50 \%$ to $74 \%$, with an average value of $-9 \%$. The contribution rates of precipitation were between $-46 \%$ and $100 \%$, and the average is $61 \%$. According to this result, the variation of precipitation was the main reason that the northeast, central, and western 


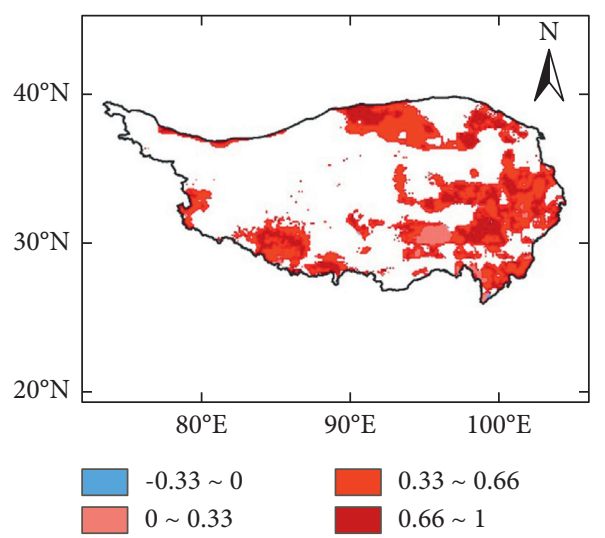

(a)

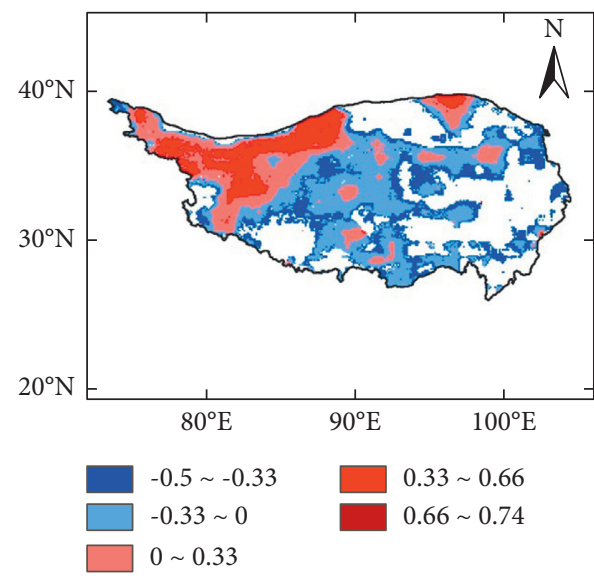

(c)

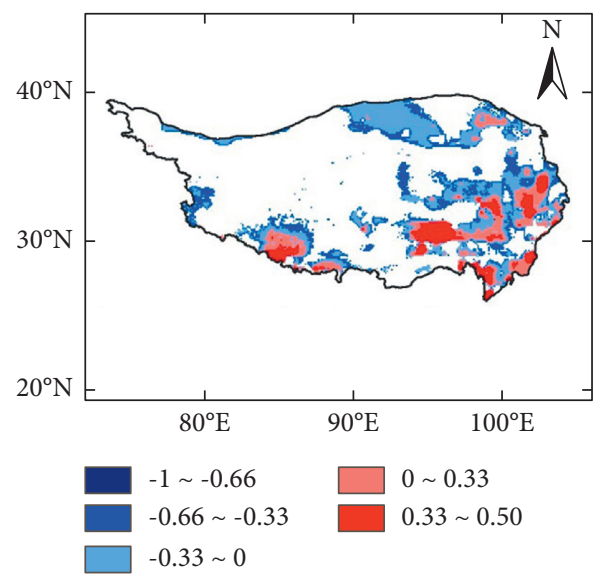

(b)

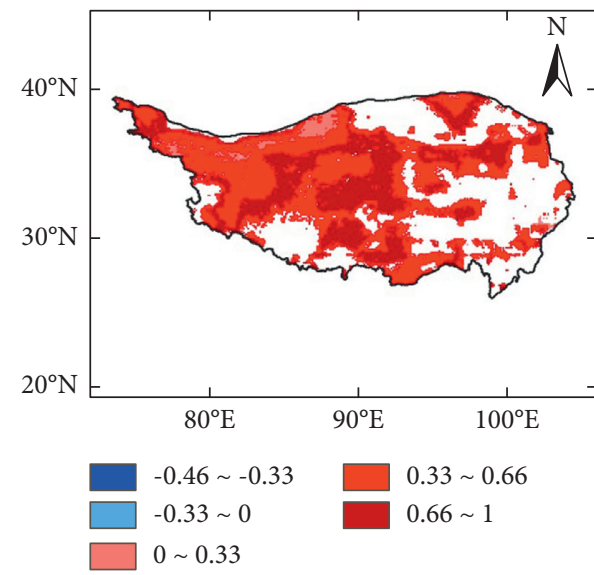

(d)

FIGURE 6: The respective contribution rate of the precipitation and temperature variability to the SPEI trend in the QTP. (a) and (b) are the contribution rates of the precipitation and temperature variability in the regions tending to be drier, and (c) and (d) are the contribution rates in the regions tending to be wetter. (a) $C r \_$temperature. (b) $C r \_$precipitation. (c) $C r \_$temperature. (d) $C r \_$precipitation.

parts of the QTP tended to be wetter, which was different from the regions that tend to be drier. Spatially, the Crvalues of temperature and precipitation are both positive in the northeast and western parts of the QTP. However, in most of the central parts, $\mathrm{Cr}$ values of precipitation are positive, but $\mathrm{Cr}$ values of temperature are negative.

\section{Discussion}

4.1. Comparison with Previous Studies. In previous studies, $\mathrm{Li}$ et al. [63] applied SPEI to characterize the drought conditions in the southeast part of the QTP during 1982-2012, and the results explicitly showed a drying trend. Chen et al. [41] calculated six drought indexes with meteorological grid data at 0.5 degree resolution, analyzed the change trend of drought and wetness in different climatic regions of China, and concluded that the QTP had an obvious trend of wetting. The above conclusions are highly consistent with ours, indicating that the conclusions obtained in this study are credible. In the western part, Li et al. [64] concluded that dryness conditions were aggravating during the period 1971-2014 across Tibet. However, we found that Tibet was showing a wetting trend in the period of 1979-2015. It should be noted that Li et al. [64] assessed the drought condition over Tibet only based on meteorological data from 38 stations, and these stations are mainly concentrated in the south of Tibet. In our study, both stations and CMFD pixels showed that drought conditions were aggravating in the same regions. However, in the north and central Tibet, most areas showed obvious wetting trends, which means that only the observed data cannot truly reflect the overall drought and wetness trend in Tibet.

\subsection{Drought and Wetness Variability in Different Climate} Regions. Previous studies have shown that most wet regions were becoming wetter and dry regions were becoming drier under global warming $[9,65]$, and the trend of drought and wetness in different climatic zones of the QTP is not clear. The China Meteorological Administrations takes the cumulative temperature with the daily average temperature of no less than $10^{\circ} \mathrm{C}$ and the multi-year average value of the temperature in the coldest month as the heat index and the dryness as the moisture index and divides China into 32 


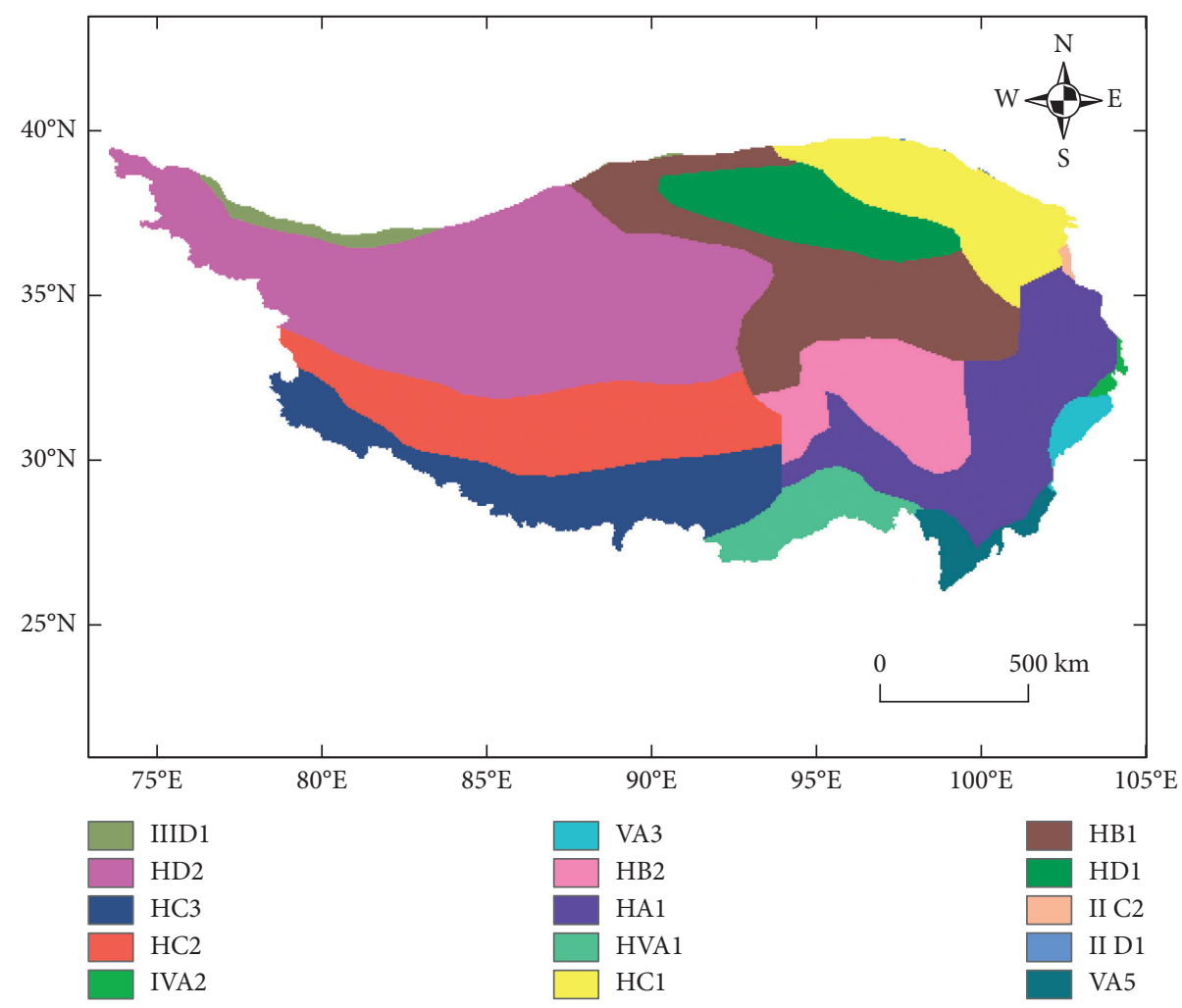

FIgURE 7: The climate regionalization in the QTP.

secondary climate regions [66], including 15 climate regions in the QTP (Figure 7). These 15 climate regions are Southern Xinjiang (IIID1), Northern Tibet (HD2), Southern Tibet (HC3), Central Tibet (HC2), Qinba (IVA2), Sichuan (VA3), Changdu (HB2), Bomi and Western Sichuan (HA1), Dawang and Zayu (HVA1), Qilian and Qinghai Lake (HC1), Southern Qinghai (HB1), Qaidam (HD1), Central Inner Mongolia (IIC2), Inner Mongolia and Gansu (IID1), and North Yunnan (VA5). Among these climatic zones, Qinba, Sichuan, Bomi and Western Sichuan, Dawang and Zayu, and North Yunnan belong to the humid regions, Changdu and Southern Qinghai belong to the semihumid regions, Southern Xinjiang, Northern Tibet, Qaidam, and Inner Mongolia and Gansu belong to the arid regions, and Southern Tibet, Central Tibet, Qilian and Qinghai Lake, and Central Inner Mongolia belong to the semiarid regions.

Previous studies had shown that the SPEI at 12-month time scale (SPEI-12) is suitable for describing the long-term drought and wetness trend [67]. In this study, we also selected SPEI-12 to analyze the characteristics of drought and wetness changes in different climatic regions of the QTP. Following the variation trend of SPEI-12 from each CMFD grid, the percentages of areas tending to be drier and wetter significantly $(p<0.1)$ in different climate zone were also calculated (Figure 8). As shown in Figure 8, climate regions tending to be drier significantly include Southern Xinjiang, Qinba, Sichuan, Changdu, Bomi and Western Sichuan, Qaidam, Inner Mongolia and Gansu, and North Yunnan. Climate regions tending significantly to be wetter include Northern Tibet, Southern Tibet, Central Tibet, Dawang and

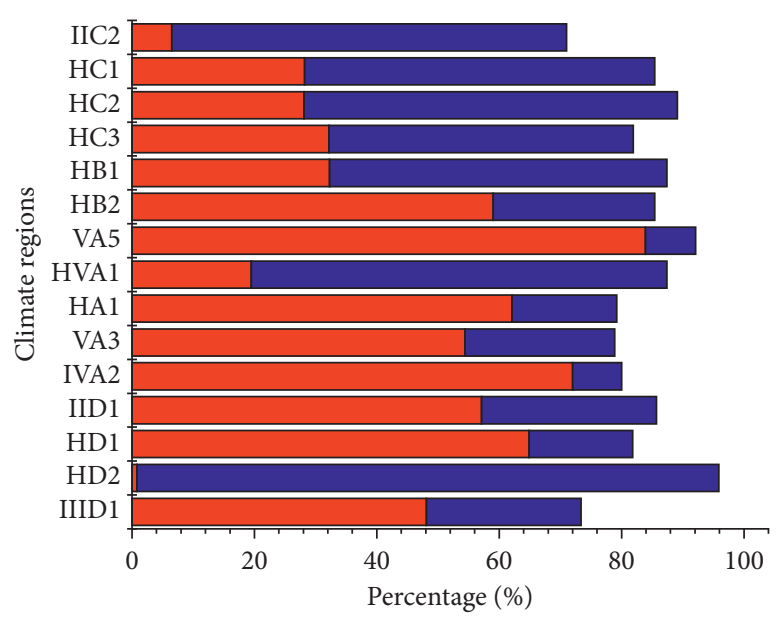

Figure 8: Percentages of areas tending to be drier (red bar) and wetter (blue bar) significantly $(p<0.1)$ in different climate regions based on the trend of SPEI-12 in the QTP during 1979-2015.

Zayu, Qilian and Qinghai Lake, Southern Qinghai, and Central Inner Mongolia. According to this result, most of the arid and humid regions in the QTP tended to be drier, while the semiarid regions tended to be wetter.

\section{Conclusion}

This study investigated the drought and wetness trend and the respective contributions of temperature and precipitation variability by using SPEI calculated based on the 
observed and CMFD dataset in the QTP during 1979-2015. The main results are summarized as follows:

(1) The SPEI series based on the observed and CMFD data showed that the southeast of the QTP and the Qaidam Basin in the northeast tended to be drier during 1979-2015, but most areas in the middle and west of the plateau tended to be wetter. The SPEI sequence obtained by averaging all CMFD grid points revealed that the whole QTP tends to be wetter during the study period.

(2) On the whole, the probability of drought was decreasing and the probability of wetness was increasing in the QTP during 1979-2015. In regions that tended to be drier, the probabilities of mild drought, moderate drought, and extreme drought were also increasing, while in areas that tend to be wetter, the probabilities of all $l$ grades of drought were decreasing.

(3) In the drier regions, temperature is the dominant factor controlling the change trend of SPEI, the average contribution rate of temperature is $60 \%$, and the contribution rate of precipitation is only $-11 \%$. In the wetter regions, the contribution rate of precipitation is much higher than that of temperature. The average contribution rate of precipitation is $61 \%$ and that of temperature is $-9 \%$.

(4) The statistical results in different climatic regions of the QTO showed that most of the arid and humid regions in the QTP tended to be drier, while the semiarid regions tended to be wetter.

\section{Nomenclature}

$p_{i}$ : $\quad$ Probability of $i$ th drought and wetness category

$f_{i}$ : $\quad$ Frequency of $i$ th drought and wetness category

$p: \quad$ Significance level of the Mann-Kendall test

$S P E I_{o}$ : $\quad$ SPEI series calculated using the original meteorological data

$S P E I_{D p}$ : $\quad$ SPEI series calculated using the original temperature and detrended precipitation

$S P E I_{D t}$ : $\quad$ SPEI series calculated using the detrended temperature and original precipitation

$S \_S P E I_{o}: \quad$ Linear slope of $S P E I_{o}$ series

$S \_S P E I_{D p}$ : Linear slope of $S P E I_{D p}$ series

$S \_S P E I_{D t}$ : Linear slope of $S P E I_{D t}$ series

$C r \_T$ : Contribution rate of temperature to SPEI variation

$C r \_P$ : Contribution rate of precipitation to SPEI variation

Cr_O : Contribution rate of other factors to SPEI variation.

\section{Data Availability}

The CMFD dataset can be downloaded directly from the National Tibetan Plateau Data Center (https://data.tpdc.ac. $\mathrm{cn} /$ ). Climatic zone data of the QTP were adapted from the climatic regionalization data of China and can be downloaded from the Resource and Environment Data Science Cloud Platform and Data Center (https://www. resdc.cn). The observed data were provided by the National Meteorological Information Center (https://data.cma. $\mathrm{cn} /)$.

\section{Conflicts of Interest}

The authors declare that they have no conflicts of interest.

\section{Acknowledgments}

This research was supported by the National Natural Science Foundation of China (42171467, 42001060, and 41705139) and the Basic Research Project of Qinghai Province (2021ZJ-947Q). The authors also thank the National Tibetan Plateau Data Center, Resource and Environment Science and Data Center in Beijing, and China Meteorological Administration for providing the meteorological data for this study.

\section{References}

[1] D. J. Lorenz, J. A. Otkin, M. Svoboda, C. R. Hain, M. C. Anderson, and Y. Zhong, "Predicting U.S. drought monitor states using precipitation, soil moisture, and evapotranspiration anomalies. Part I: development of a nondiscrete USDM index," Journal of Hydrometeorology, vol. 18, no. 7, pp. 1943-1962, 2017.

[2] T.-W. Kim and M. Jehanzaib, "Drought risk analysis, forecasting and assessment under climate change," Water, vol. 12, no. 7, 1862 pages, 2020.

[3] Y. Xu, V. Ramanathan, and D. G. Victor, "Global warming will happen faster than we think," Nature, vol. 564, no. 7734, pp. 30-32, 2018.

[4] C.-E. Park, S.-J. Jeong, M. Joshi et al., "Keeping global warming within $1.5^{\circ} \mathrm{C}$ constrains emergence of aridification," Nature Climate Change, vol. 8, no. 1, pp. 70-74, 2018.

[5] X. Tan, Y. Wu, B. Liu, and S. Chen, "Inconsistent changes in global precipitation seasonality in seven precipitation datasets," Climate Dynamics, vol. 54, no. 5, pp. 3091-3108, 2020.

[6] M. G. Donat, A. L. Lowry, L. V. Alexander, P. A. O'Gorman, and N. Maher, "More extreme precipitation in the world's dry and wet regions," Nature Climate Change, vol. 6, no. 5, pp. 508-513, 2016.

[7] G. Myhre, K. Alterskjær, C. W. Stjern et al., "Frequency of extreme precipitation increases extensively with event rareness under global warming," Scientific Reports, vol. 9, no. 1, pp. 16063-16110, 2019.

[8] T. Yang, J. Ding, D. Liu, X. Wang, and T. Wang, "Combined use of multiple drought indices for global assessment of dry gets drier and wet gets wetter paradigm," Journal of Climate, vol. 32, no. 3, pp. 737-748, 2019.

[9] L. Gao and Y. Zhang, "Spatio-temporal variation of hydrological drought under climate change during the period 19602013 in the Hexi Corridor, China," Journal of Arid Land, vol. 8, no. 2, pp. 157-171, 2016.

[10] H. Madsen, D. Lawrence, M. Lang, M. Martinkova, and T. R. Kjeldsen, "Review of trend analysis and climate change projections of extreme precipitation and floods in Europe," Journal of Hydrology, vol. 519, pp. 3634-3650, 2014.

[11] H. C. Winsemius, B. Jongman, T. I. E. Veldkamp, S. Hallegatte, M. Bangalore, and P. J. Ward, "Disaster risk, 
climate change, and poverty: assessing the global exposure of poor people to floods and droughts," Environment and Development Economics, vol. 23, no. 3, pp. 328-348, 2018.

[12] X. Li, Q. You, G. Ren et al., "Concurrent droughts and hot extremes in northwest China from 1961 to 2017," International Journal of Climatology, vol. 39, no. 4, pp. 2186-2196, 2019.

[13] Y. Zhao, Z. Weng, H. Chen, and J. Yang, "Analysis of the evolution of grought, flood, and drought-flood abrupt alternation events under climate change using the daily SWAP index," Water, vol. 12, no. 7, Article ID 1969, 2020.

[14] W. Palmer, Meteorological Drought, US Department of Commerce Weather Bureau, Washington DC, WAS, USA, 1965.

[15] T. McKee, N. Doesken, and J. Kleist, "The relationship of drought frequency and duration to time scales," in Proceedings of the 8th Conference on Applied Climatology, Anaheim, CA, USA, January 1993.

[16] H. Wu, M. J. Hayes, A. Weiss, and Q. Hu, "An evaluation of the standardized precipitation index, the China- $Z$ index and the statistical Z-score," International Journal of Climatology, vol. 21, no. 6, pp. 745-758, 2001.

[17] S. M. Vicente-Serrano, S. Beguería, and J. I. López-Moreno, "A multiscalar drought index sensitive to global warming: the standardized precipitation evapotranspiration index," Journal of Climate, vol. 23, no. 7, pp. 1696-1718, 2010.

[18] M. R. Keshavarz, M. Vazifedoust, and A. Alizadeh, "Drought monitoring using a Soil Wetness Deficit Index (SWDI) derived from MODIS satellite data," Agricultural Water Management, vol. 132, pp. 37-45, 2014.

[19] A. R. Zarei, "Analysis of changes trend in spatial and temporal pattern of drought over south of Iran using standardized precipitation index (SPI)," SN Applied Sciences, vol. 1, no. 5, pp. 1-14, 2019.

[20] D. Suroso, A. Nadhilah, and E. Aldrian, "Drought detection in java island based on standardized precipitation and evapotranspiration index (SPEI)," Journal of Water and Climate Change, vol. 12, no. 6, pp. 2734-2752, 2021.

[21] M. H. Lee, E. S. Im, and D. H. Bae, "A comparative assessment of climate change impacts on drought over Korea based on multiple climate projections and multiple drought indices," Climate Dynamics, vol. 53, no. 1, pp. 389-404, 2019.

[22] Z. Zeng, W. Wu, Y. Li et al., "Spatiotemporal variations in drought and wetness from 1965 to 2017 in China," Water, vol. 12, no. 8, Article ID 2097, 2020.

[23] Q. Huang, Q. Zhang, V. P. Singh, P. Shi, and Y. Zheng, "Variations of dryness/wetness across China: changing properties, drought risks, and causes," Global and Planetary Change, vol. 155, pp. 1-12, 2017.

[24] T. M. Vu, S. V. Raghavan, S.-Y. Liong, and A. K. Mishra, "Uncertainties of gridded precipitation observations in characterizing spatio-temporal drought and wetness over Vietnam," International Journal of Climatology, vol. 38, no. 4, pp. 2067-2081, 2018.

[25] J. H. Stagge, D. G. Kingston, L. M. Tallaksen, and D. M. Hannah, "Observed drought indices show increasing divergence across Europe," Scientific Reports, vol. 7, no. 1, pp. 14045-14110, 2017.

[26] N. R. Patel, P. Chopra, and V. K. Dadhwal, "Analyzing spatial patterns of meteorological drought using standardized precipitation index," Meteorological Applications, vol. 14, no. 4, pp. 329-336, 2007.

[27] W. Lou, L. Wu, Y. Mao, and K. Sun, "Precipitation and temperature trends and dryness/wetness pattern during
1971-2015 in Zhejiang Province, southeastern China," Theoretical and Applied Climatology, vol. 133, no. 1, pp. 47-57, 2018.

[28] H. Tao, H. Borth, K. Fraedrich, B. Su, and X. Zhu, "Drought and wetness variability in the Tarim River Basin and connection to large-scale atmospheric circulation," International Journal of Climatology, vol. 34, no. 8, pp. 2678-2684, 2014.

[29] S. Chen, T. Y. Gan, X. Tan, D. Shao, and J. Zhu, “Assessment of CFSR, ERA-Interim, JRA-55, MERRA-2, NCEP-2 reanalysis data for drought analysis over China," Climate Dynamics, vol. 53, no. 1-2, pp. 737-757, 2019.

[30] A. R. Zarei, A. Shabani, and M. M. Moghimi, "Accuracy assessment of the SPEI, RDI and SPI drought indices in regions of Iran with different climate conditions," Pure and Applied Geophysics, vol. 178, no. 4, pp. 1387-1403, 2021.

[31] S. Prabnakorn, S. Maskey, F. X. Suryadi, and C. de Fraiture, "Rice yield in response to climate trends and drought index in the Mun River Basin, Thailand," The Science of the Total Environment, vol. 621, pp. 108-119, 2018.

[32] P. J. Starks, J. L. Steiner, J. P. S. Neel et al., “Assessment of the standardized precipitation and evaporation index (SPEI) as a potential management tool for grasslands," Agronomy, vol. 9, no. 5, 235 pages, 2019.

[33] Y. Zhang, Z. Yu, and H. Niu, "Standardized Precipitation Evapotranspiration Index is highly correlated with total water storage over China under future climate scenarios," Atmospheric Environment, vol. 194, pp. 123-133, 2018.

[34] X. Gou, Y. Deng, F. Chen et al., "Precipitation variations and possible forcing factors on the Northeastern Tibetan Plateau during the last millennium," Quaternary Research, vol. 81, no. 3, pp. 508-512, 2014.

[35] W. W. Immerzeel, L. P. H. Van Beek, and M. F. P. Bierkens, "Climate change will affect the asian water towers," Science, vol. 328, no. 5984, pp. 1382-1385, 2010.

[36] P. Zhao, Y. Li, X. Guo et al., "The Tibetan Plateau surfaceatmosphere coupling system and its weather and climate effects: the Third Tibetan Plateau Atmospheric Science Experiment," Journal of Meteorological Research, vol. 33, no. 3, pp. 375-399, 2019.

[37] Y. Liu, M. Lu, H. Yang et al., "Land-atmosphere-ocean coupling associated with the Tibetan Plateau and its climate impacts," National Science Review, vol. 7, no. 3, pp. 534-552, 2020.

[38] C. Shi and X. Liu, "Continent drought characteristics over the Eastern Hemisphere from 1947 to 2006: analyses based on the SPEI dataset," Journal of Desert Research, vol. 32, pp. 16911701, 2012.

[39] Z. Wang, J. Li, C. Lai et al., "Does drought in China show a significant decreasing trend from 1961 to 2009?” The Science of the Total Environment, vol. 579, pp. 314-324, 2017.

[40] W. Feng, H. Lu, T. Yao, and Q. Yu, "Drought characteristics and its elevation dependence in the Qinghai-Tibet plateau during the last half-century," Scientific Reports, vol. 10, no. 1, pp. 1-11, 2020.

[41] T. Chen, H. Zhang, X. Chen et al., "Robust drying and wetting trends found in regions over China based on Köppen climate classifications," Journal of Geophysical Research: Atmosphere, vol. 122, no. 8, pp. 4228-4237, 2017.

[42] H. Deng, N. C. Pepin, Q. Liu, and Y. Chen, "Understanding the spatial differences in terrestrial water storage variations in the Tibetan Plateau from 2002 to 2016," Climatic Change, vol. 151, no. 3, pp. 379-393, 2018.

[43] W. Wan, L. Zhao, H. Xie et al., "Lake surface water temperature change over the Tibetan plateau from 2001 to 2015: a 
sensitive indicator of the warming climate," Geophysical Research Letters, vol. 45, no. 20, pp. 11177-11186, 2018.

[44] F. Zhang, X. Shi, C. Zeng et al., "Recent stepwise sediment flux increase with climate change in the Tuotuo River in the central Tibetan Plateau," Science Bulletin, vol. 65, no. 5, pp. 410-418, 2020.

[45] D. Guo, H. Wang, and D. Li, "A projection of permafrost degradation on the Tibetan Plateau during the 21st century," Journal of Geophysical Research: Atmosphere, vol. 117, Article ID D05106, 2012.

[46] R. Schiemann, D. Lüthi, P. L. Vidale, and C. Schär, "The precipitation climate of Central Asia-intercomparison of observational and numerical data sources in a remote semiarid region," International Journal of Climatology, vol. 28, no. 3, pp. 295-314, 2008.

[47] L. Zhang, L. Zhao, C. Xie et al., "Intercomparison of solid precipitation derived from the weighting rain gauge and optical instruments in the interior Qinghai-Tibetan plateau," Advances in Meteorology, vol. 2015, Article ID 936724, 11 pages, 2015.

[48] Z. Ma, Y. Xu, J. Peng et al., "Spatial and temporal precipitation patterns characterized by TRMM TMPA over the QinghaiTibetan plateau and surroundings," International Journal of Remote Sensing, vol. 39, no. 12, pp. 3891-3907, 2018.

[49] M. Ding, Q. Chen, L. Li et al., "Temperature dependence of variations in the end of the growing season from 1982 to 2012 on the Qinghai-Tibetan Plateau," GIScience and Remote Sensing, vol. 53, no. 2, pp. 147-163, 2016.

[50] M. Luo, T. Liu, F. Meng et al., "Identifying climate change impacts on water resources in Xinjiang, China," The Science of the Total Environment, vol. 676, pp. 613-626, 2019.

[51] Z. Zhou, H. Shi, Q. Fu et al., "Is the cold region in Northeast China still getting warmer under climate change impact?" Atmospheric Research, vol. 237, Article ID 104864, 2020.

[52] J. He, K. Yang, W. Tang et al., "The first high-resolution meteorological forcing dataset for land process studies over China," Scientific Data, vol. 7, no. 1, pp. 25-11, 2020.

[53] J. Sun, K. Yang, W. Guo, Y. Wang, J. He, and H. Lu, "Why has the inner Tibetan Plateau become wetter since the mid1990s?" Journal of Climate, vol. 33, no. 19, pp. 8507-8522, 2020.

[54] B. Wang, Y. Ma, Z. Su, Y. Wang, and W. Ma, "Quantifying the evaporation amounts of 75 high-elevation large dimictic lakes on the Tibetan Plateau," Science Advances, vol. 6, no. 26, Article ID eaay8558, 2020.

[55] S. Beguería, S. M. Vicente-Serrano, F. Reig, and B. Latorre, "Standardized precipitation evapotranspiration index (SPEI) revisited: parameter fitting, evapotranspiration models, tools, datasets and drought monitoring," International Journal of Climatology, vol. 34, no. 10, pp. 3001-3023, 2014.

[56] C.-Y. Xu and V. P. Singh, "Evaluation and generalization of temperature-based methods for calculating evaporation," Hydrological Processes, vol. 15, no. 2, pp. 305-319, 2001.

[57] B. Shi, X. Zhu, Y. Hu, and Y. Yang, "Drought characteristics of henan province in 1961-2013 based on standardized precipitation evapotranspiration index," Journal of Geographical Sciences, vol. 27, no. 3, pp. 311-325, 2017.

[58] H. B. Mann, "Nonparametric tests against trend," Econometrica, vol. 13, no. 3, pp. 245-259, 1945.

[59] M. G. Kendall, Rank Correlation Methods, Springer, London, UK, 1975.

[60] M. Shadmani, S. Marofi, and M. Roknian, "Trend analysis in reference evapotranspiration using mann-kendall and spearman's rho tests in arid regions of Iran," Water Resources Management, vol. 26, no. 1, pp. 211-224, 2012.

[61] G. Wang, T. Gong, J. Lu, D. Lou, D. F. T. Hagan, and T. Chen, "On the long-term changes of drought over China (19482012) from different methods of potential evapotranspiration estimations," International Journal of Climatology, vol. 38, no. 7, pp. 2954-2966, 2018.

[62] J. Wu and X. Chen, "Spatiotemporal trends of dryness/wetness duration and severity: the respective contribution of precipitation and temperature," Atmospheric Research, vol. 216, pp. 176-185, 2019.

[63] X. Li, B. He, X. Quan, Z. Liao, and X. Bai, "Use of the standardized precipitation evapotranspiration index (SPEI) to characterize the drying trend in southwest China from 19822012," Remote Sensing, vol. 7, no. 8, pp. 10917-10937, 2015.

[64] S. Li, Z. Yao, Z. Liu, R. Wang, M. Liu, and J. C. Adam, "The spatio-temporal characteristics of drought across Tibet, China: derived from meteorological and agricultural drought indexes," Theoretical and Applied Climatology, vol. 137, no. 34, pp. 2409-2424, 2019.

[65] C. Liu and R. P. Allan, "Observed and simulated precipitation responses in wet and dry regions 1850-2100," Environmental Research Letters, vol. 8, Article ID 034002, 2013.

[66] The Chinese Academy of Science on Natural Regionalization Commission, Climate Regionalization of China, Science Press, Beijing, China, 1959.

[67] X. Gao, Q. Zhao, X. Zhao et al., "Temporal and spatial evolution of the standardized precipitation evapotranspiration index (SPEI) in the Loess Plateau under climate change from 2001 to 2050," The Science of the Total Environment, vol. 595, pp. 191-200, 2017. 